\title{
Slot Nozzle Effects for Reduced Sonic Boom on a Generic Supersonic Wing Section
}

\author{
Raymond S. Castner* \\ NASA Glenn Research Center, Cleveland, Ohio 44135
}

\begin{abstract}
NASA has conducted research programs to reduce or eliminate the operational restrictions of supersonic aircraft over populated areas. Restrictions are due to the disturbance from the sonic boom, caused by the coalescence of shock waves formed off the aircraft. Results from two-dimensional computational fluid dynamic (CFD) analyses (performed on a baseline Mach 2.0 nozzle in a simulated Mach 2.2 flow) indicate that overexpanded and under-expanded operation of the nozzle has an effect on the $\mathrm{N}$-wave boom signature. Analyses demonstrate the feasibility of reducing the magnitude of the sonic boom $\mathrm{N}$-wave by controlling the nozzle plume interaction with the nozzle boat tail shock structure. This work was extended to study the impact of integrating a high aspect ratio exhaust nozzle or long slot nozzle on the trailing edge of a supersonic wing. The nozzle is operated in a highly under-expanded condition, creating a large exhaust plume and a shock at the trailing edge of the wing. This shock interacts with and suppresses the expansion wave caused by the wing, a major contributor to the sonic boom signature. The goal was to reduce the near field pressures caused by the expansion using a slot nozzle located at the wing trailing edge. Results from CFD analysis on a simulated wing cross-section and a slot nozzle indicate potential reductions in sonic boom signature compared to a baseline wing with no propulsion or trailing edge exhaust. Future studies could investigate if this effect could be useful on a supersonic aircraft for main propulsion, auxiliary propulsion, or flow control.
\end{abstract}

\section{Nomenclature}

$\mathrm{Cfg}=$ Thrust Coefficient $=\mathrm{Fg} / \mathrm{Fi}$

$\mathrm{Fg}=$ Gross Thrust $(\mathrm{lb})=\mathrm{m}_{9} \mathrm{~V}_{9}+\left(\mathrm{P}_{9}-\mathrm{P}_{\infty}\right) \mathrm{A}_{9}$

$\mathrm{Fi}=$ Ideal Thrust $=\mathrm{m}_{9} \mathrm{~V}_{9}$

$\mathrm{m}_{9}=$ Mass Flow, Nozzle Exit (lb/sec)

$\mathrm{NPR}=$ Nozzle Pressure Ratio $=\mathrm{Pt} / \mathrm{P}_{\infty}$

$\mathrm{P}=$ Local Static Pressure, (psia)

$\mathrm{Pt}=$ Total Pressure in Nozzle (psia)

$\mathrm{P}_{\infty}=$ Free Stream Static Pressure (psia)

$\mathrm{P}_{9}=$ Static Pressure, Nozzle Exit (psia)

$\Delta \mathrm{P} / \mathrm{P}_{\infty}=\left(\mathrm{P}-\mathrm{P}_{\infty}\right) / \mathrm{P}_{\infty}$

$\mathrm{V}_{9}=$ Velocity, Nozzle Exit $(\mathrm{ft} / \mathrm{sec})$

\section{Introduction}

$\mathrm{B}$ OTH NASA and the US aerospace industry have studied technology for economically viable supersonic flight, with emphasis on reducing the sonic boom. Recent interest has also focused on development of a supersonic business jet. Reductions in the sonic boom would provide for improved economic viability and an increased market potential for both a high speed commercial airliner or a supersonic business jet which could operate unrestricted over land and populated areas. A number of studies and tests have been performed and results indicate that a reduction in the sonic boom signature for supersonic transport aircraft may be possible. Examples are the SSBD ${ }^{1}$ and the Quiet Spike, ${ }^{2}$ which have validated forward shaping technologies for reduction of the sonic boom generated by forward aircraft structures. Studies have also considered reductions in the sonic boom caused by aft aircraft structures and components such as the tail, engines and nozzles; examples include reports by Castner ${ }^{3}$ and Bui. ${ }^{4}$

\footnotetext{
${ }^{*}$ Aerospace Engineer, Inlet and Nozzle Branch, 21000 Brookpark Road, and AIAA Senior Member.
} 


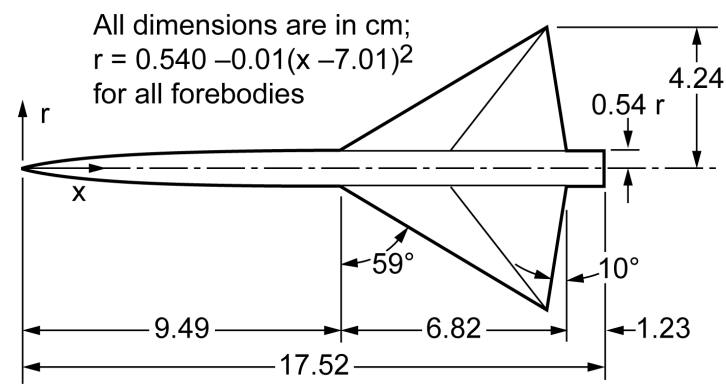

Figure $1.59^{\circ}$ delta wing-body model.

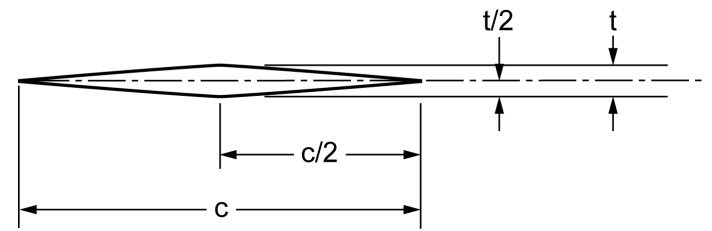

Figure 2. Wing cross section.

In previous work by Putnam and Capone, ${ }^{5}$ a variety of nozzles were tested from a fully expanded Mach 1.7 nozzle to a fully expanded Mach 2.9 nozzle. Their study was conducted in a wind tunnel, where near field pressure measurements were made at one nozzle diameter away from the model. Wind tunnel conditions were Mach 2.2 at a simulated altitude of 50,000 ft. Based on this work, Castner ${ }^{3}$ performed a two-dimensional Computational Fluid Dynamics (CFD) study. For this study, Putnam and Capone's "Nozzle 6" was selected as a baseline Mach 2.0 nozzle in a simulated Mach 2.2 flow field. During the analysis, it was determined that over-expanded and under-expanded operation of the nozzle has an effect on the N-wave sonic boom signature. Results demonstrated the feasibility of reducing the magnitude of the sonic boom $\mathrm{N}$-wave by controlling the nozzle plume interaction with the nozzle boat tail shock structure. Similar trends were observed with a two-dimensional slot nozzle.

The present study investigates reducing the near field pressure signature, and sonic boom signature, for a supersonic wing section. The goal is to investigate potential uses of a slot nozzle for main propulsion, auxiliary propulsion, or flow control on potential supersonic aircraft. A simplified aircraft geometry was available from NASA TN-D-7160, by Hunton et al. ${ }^{6}$ This configuration was the $59^{\circ}$ delta wing-body, shown in Fig. 1 . This configuration possessed a simplified baseline supersonic wing geometry, given in Fig. 2. The supersonic wing geometry was paired with the slot nozzle geometry as a basis for a study on reducing the expansion wave from a wing, similar to reducing the boat tail expansion on an isolated nozzle. For simplicity, the $59^{\circ}$ delta wing-body wing was transformed into a two-dimensional wing analysis based on geometry at the wing root.

\section{Analysis}

\section{A. Computational Domain and Grid}

Four geometric configurations were studied and are summarized below as: (1) the baseline wing, (2) the wing with integrated slot nozzle, (3) the wing with $1^{\circ}$ angle of attack, and (4) the wing with integrated slot nozzle at $1^{\circ}$ angle of attack.

\section{Baseline Wing}

Simulations were based on a two-dimensional wing geometry taken from the wing root of the $59^{\circ}$ delta wing body, displayed in Figs. 1 and 2 (NASA TN-D-7160, Fig. 1-a-1). The baseline wing was modeled with 307,000 grid points, arranged in a structured grid with 23 blocks, see Fig. 3(a). The computational domain was 40.8 in. long (5.98 chord lengths) and 16.2 in. tall (2.38 chord lengths). Block structure was aligned with the shock waves formed off the wing. Dimensions from the original report were in centimeters, but the wing was modeled in inches. This modeling error is consistent throughout the report and does not affect the results. This wing section had a $6.82 \mathrm{in}$. chord length with 0.341 in. thickness. Only the top half was modeled as seen in Fig. 3(b).

2. Wing With Integrated Slot Nozzle

The baseline wing was modeled with an integrated slot nozzle, which consisted of 314,000 grid points, arranged in 22 blocks. Free stream conditions were Mach 2.2. A slot nozzle was designed for placement at the wing trailing edge, and was placed under the half-wing as shown in Fig. 4. Based on previous research with isolated nozzles, a highly under-expanded nozzle design was desired. Placement of the nozzle does not reflect a real configuration, as the nozzle is placed under the wing centerline as a simple demonstration, but the next design adds reality to this configuration. The strong shock structure from this nozzle would interact with the strong expansion from the wing. A Mach 1.4 nozzle was selected based on CFD analysis and screening of preliminary plume shapes. The nozzle design was obtained with a method of characteristics design code, which produced a nozzle with Mach 1.4 exit conditions at a design nozzle pressure ratio of 8.0. Modeling consisted of one-half of the nozzle with a 0.094 exit height and a 0.084 throat height. Although this is not a three-dimensional geometry, the slot nozzle height was designed to simulate a slot nozzle on the trailing edge of the wing on the $59^{\circ}$ delta wing-body. Nozzle throat area 


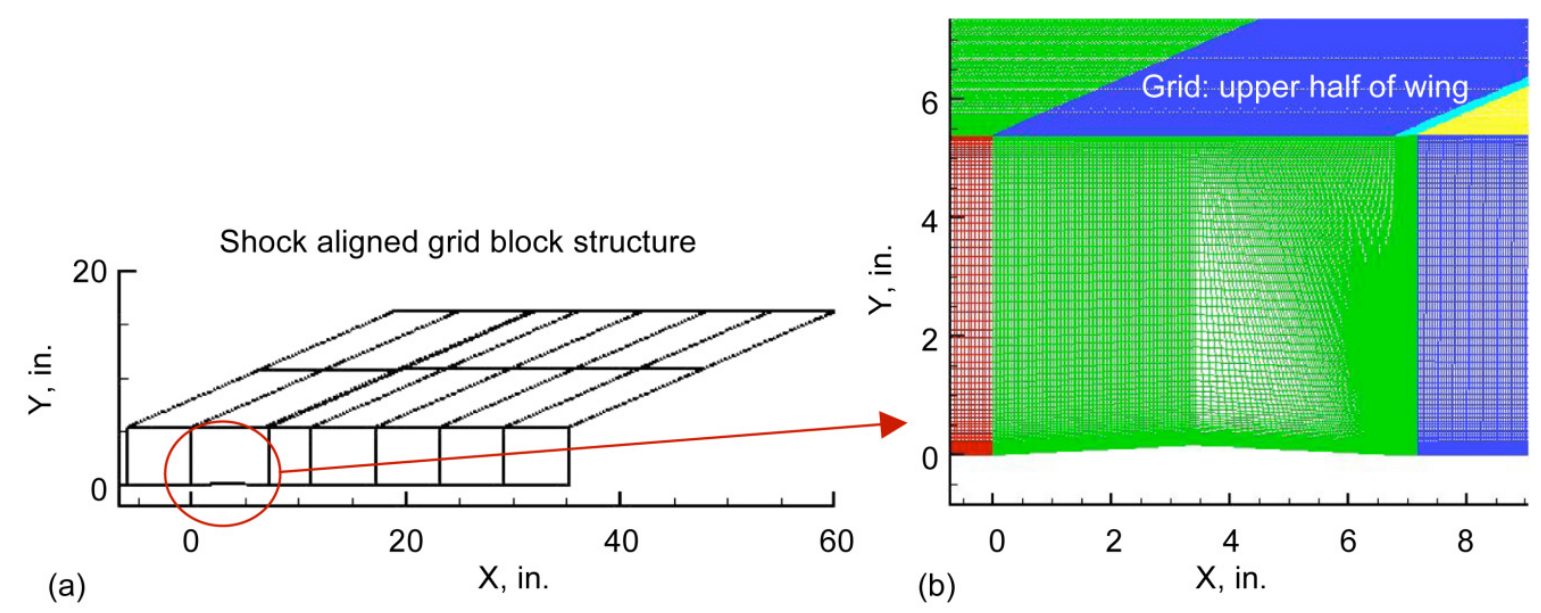

Figure 3. (a)Computational block structure for baseline wing. (b) Close-up of wing contour.

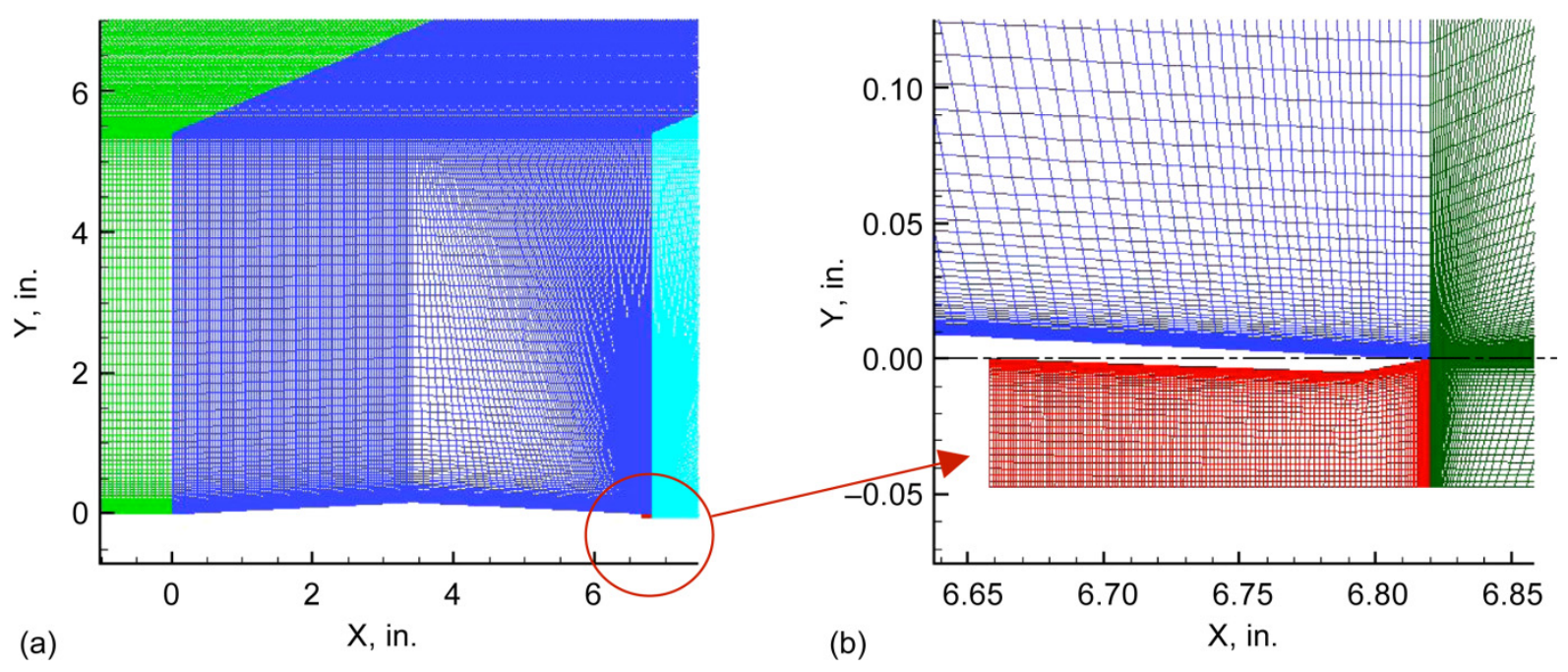

Figure 4. (a) Close-up of wing with integrated slot nozzle. (b) Slot nozzle details.

matched the area of the Putnam and Capone "Nozzle 6", as rescaled for the back of the $59^{\circ}$ delta wing body fuselage. This configuration would simulate a single engine propulsion configuration with throat area of 0.666 in. ${ }^{2}$. Again, for a simple demonstration, only the top half of a two-dimensional wing section and nozzle were modeled, matching the wing section at the root of the $59^{\circ}$ delta wing body model.

3. Wing at $1^{\circ}$ Angle of Attack

For the wing configuration at $1^{\circ}$ angle of attack, the grid consisted of 384,000 grid points arranged in 28 structured blocks, see Fig. 5(a). Again, blocks were aligned with shock structures. The wing was made to be longer and thicker to accommodate the slot nozzle which follows, keeping the same leading edge wedge angle. Overall length was 8.822 in., and thickness was 0.435 in. Both the top and bottom of this wing were modeled, with details shown in Fig. 5(b). Free stream conditions were Mach 2.2 with a minus $1^{\circ}$ angle of attack; the model is flying upside down in this simulation.

4. Wing With Integrated Slot Nozzle at $1^{\circ}$ Angle of Attack

The wing with slot nozzle had 435,000 grid points, arranged in 29 structured blocks. The same nozzle design was kept with Mach 1.4 exit conditions and a design NPR 8. This nozzle was integrated into the wing, which was made to be longer and thicker to accommodate the slot nozzle, with the same leading edge wedge angle. Overall length was 7.822 in., and thickness was 0.435 in. Again, free stream conditions were Mach 2.2 with a minus $1^{\circ}$ angle of attack; the model is again upside down in this simulation. The nozzle design is visible in Fig. 6 . 

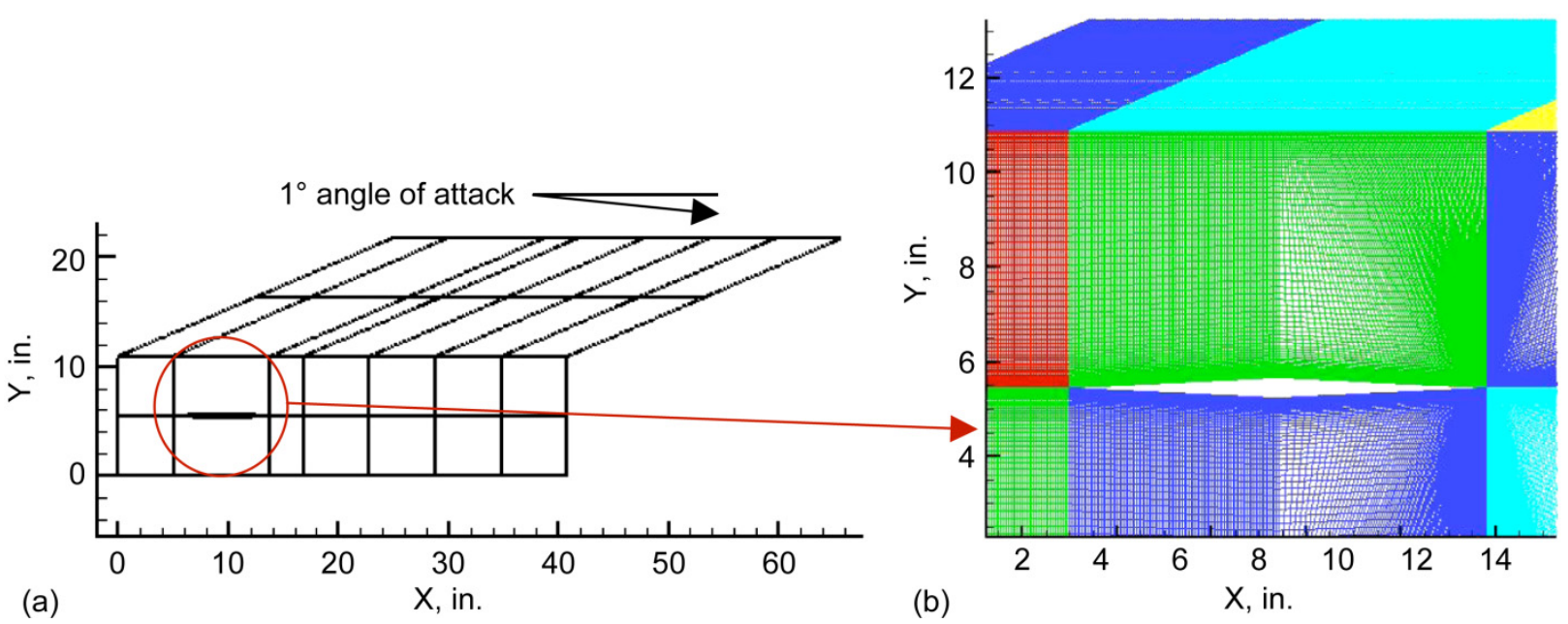

Figure 5. (a) Computational domain for wing at $1^{\circ}$ angle of attack. (b) Detail of wing at angle of attack.

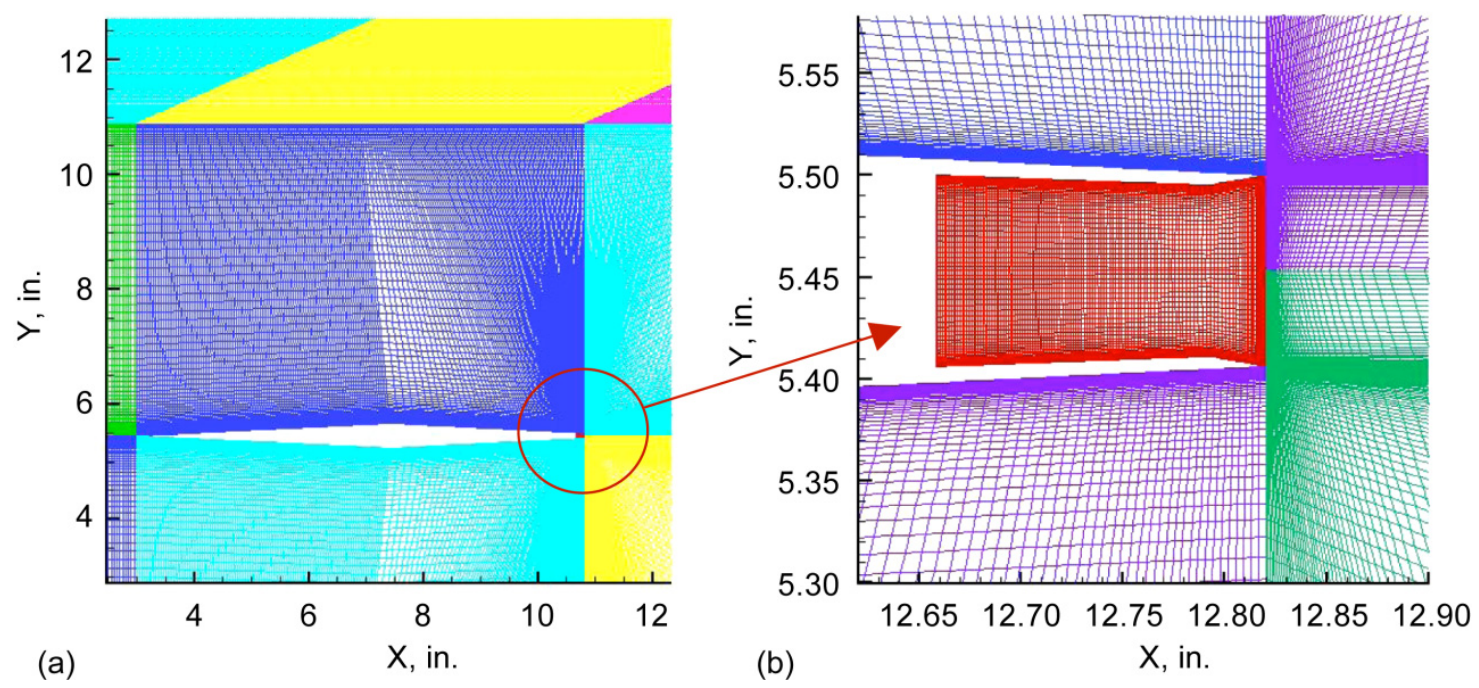

Figure 6. (a) Computational domain for wing with integrated slot nozzle at $1^{\circ}$ angle of attack. (b) Detail of nozzle at angle of attack.

\section{B. Computational Algorithm \\ 1. Wind-US}

Wind-US is a computational platform that numerically solves various sets of equations governing physical phenomena. ${ }^{7}$ The code supports the solution of the Euler and Navier-Stokes equations of fluid mechanics, along with supporting equation sets governing turbulent and chemically-reacting flows. The current version of Wind-US is 2.0. Wind-US was used with the modified second-order Roe upwind scheme for stretched grids, implicit time stepping with a Courant-Friedrichs-Levy (CFL) number of 1.0, and the shear stress transport (SST) turbulence model. 


\section{Results}

\section{A. Baseline Wing}

Mach number contours are shown in Fig. 7 for the baseline wing configuration at Mach 2.2 and $0^{\circ}$ angle of attack. Visible are a clear shock and compression from the leading edge and forward part of the wing, followed by a dramatic expansion; and finally a shock back to ambient pressure. This pressure signature, $\Delta \mathrm{P} / \mathrm{P}$, from the wing was plotted at a distance of 15 in. above the wing centerline, or 1.7 chord lengths. The signature mimics the classic $\mathrm{N}$ wave pattern for a supersonic aircraft, presented in Fig. 8, and creates a significant contribution to the ground observed sonic boom signature. For this two-dimensional wing configuration, the peak overpressure approaches a $\Delta \mathrm{P} / \mathrm{P}$ of 0.2 , with a minimum value of -0.125 at the right portion of the $\mathrm{N}$-wave, or near field pressure signature.

\section{B. Wing With Integrated Slot Nozzle}

Figure 9(a) gives the Mach number contours for the wing configuration with an integrated slot nozzle. As explained earlier, the nozzle selection was based on previous research with isolated nozzles, where a highly underexpanded nozzle design was desired. The strong shock structure from this nozzle would interact with the strong expansion from the wing. A Mach 1.4 nozzle operating in a Mach 2.2 air stream was selected based on CFD screening of preliminary plume shapes. The nozzle was operating at NPR 18, and was highly under-expanded as shown in Fig. 9(b). Comparisons can be made to Fig. 7, the baseline wing. The main comparison was the reduction in expansion from the trailing half of the wing surface. Turning of the flow around the under-expanded nozzle plume created a strong shock at the wing trailing edge. Strong differences are not noticeable near the wing surface, but when observed at a distance from the upper wing surface, the nozzle lip shock overtakes the expansion created by the wing. Figures 10 and 11 are provided to show how a reduction in NPR to 16 and 14 show similar effect, although the differences are subtle. Each of these Mach number contours show the benefit of under-expanded nozzle operation on the wing expansion, when viewed at values of more than $5 \mathrm{in}$. above the wing surface.

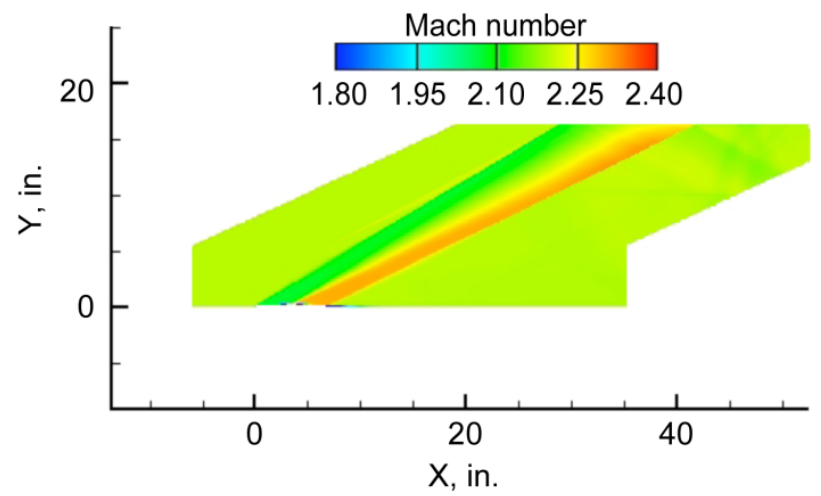

Figure 7. Mach number contours for baseline wing.

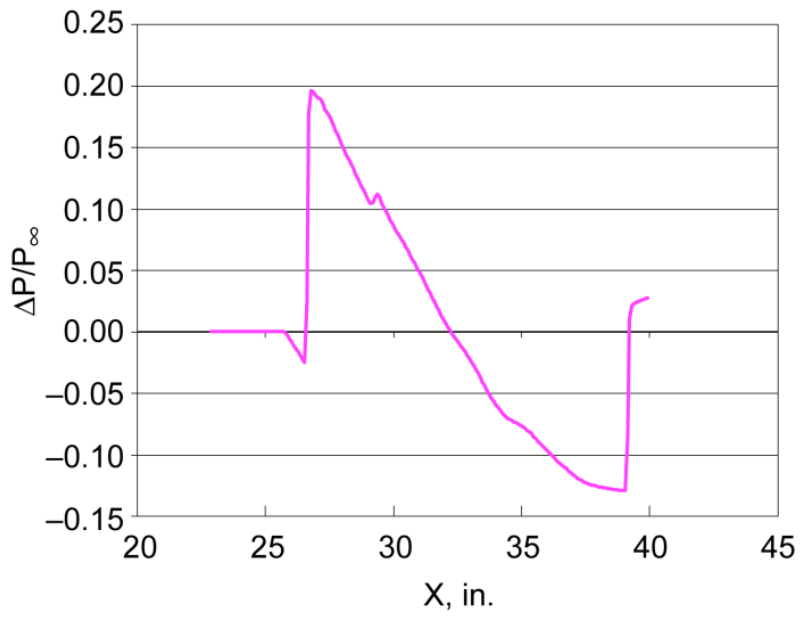

Figure 8. $\Delta P / P_{\infty}$ for baseline wing at $y=15$ in. from centerline (1.7 chord lengths). 


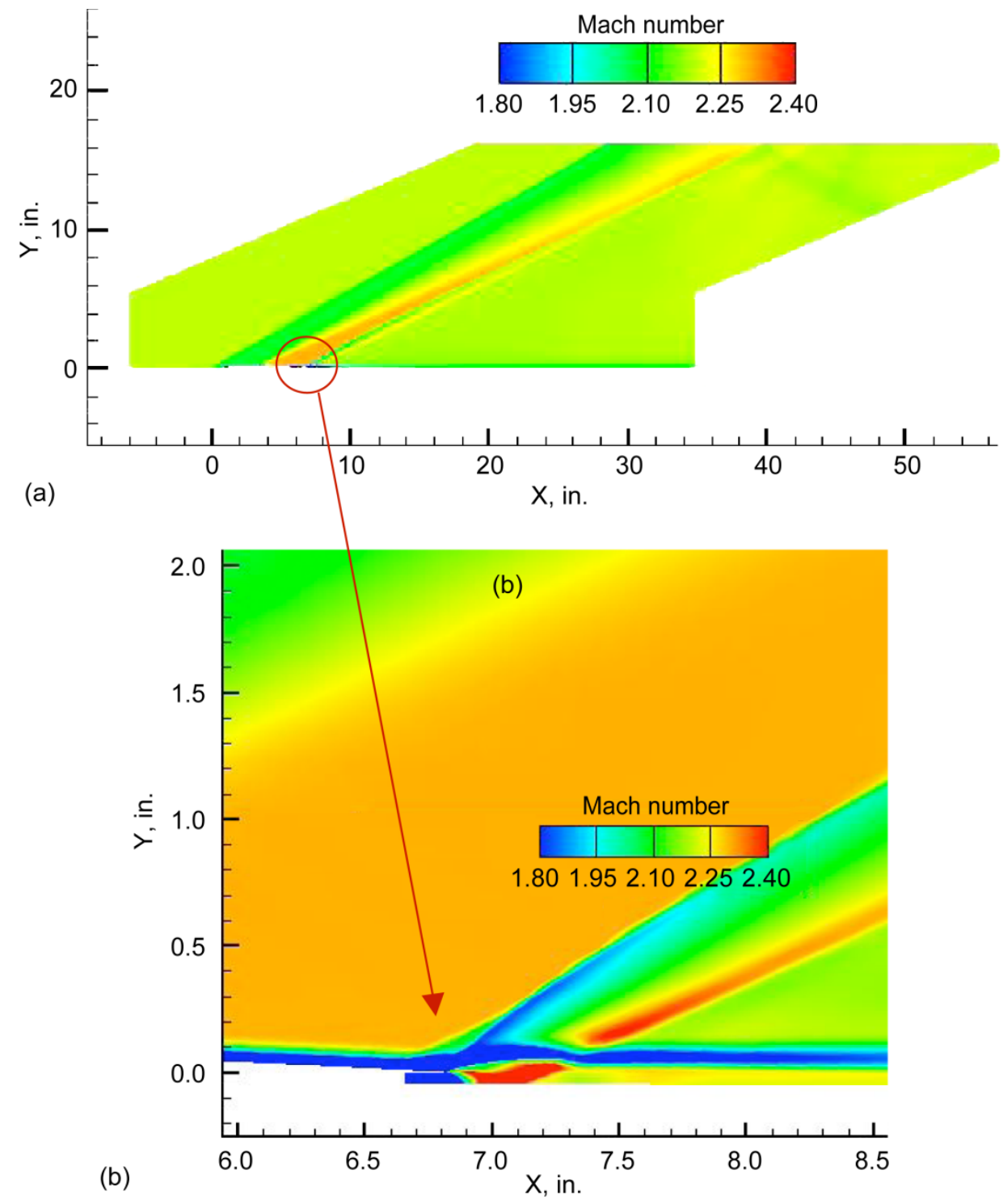

Figure 9. Mach number contours for integrated wing with slot nozzle, NPR $=18$. (b) Close-up of slot nozzle at trailing edge of wing.

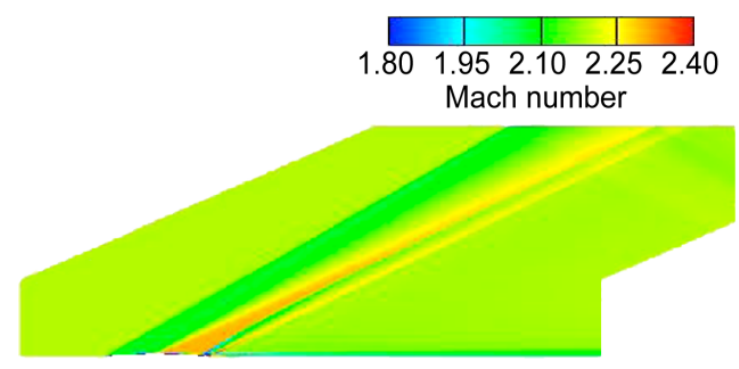

Figure 10. Slot nozzle at NPR 14.

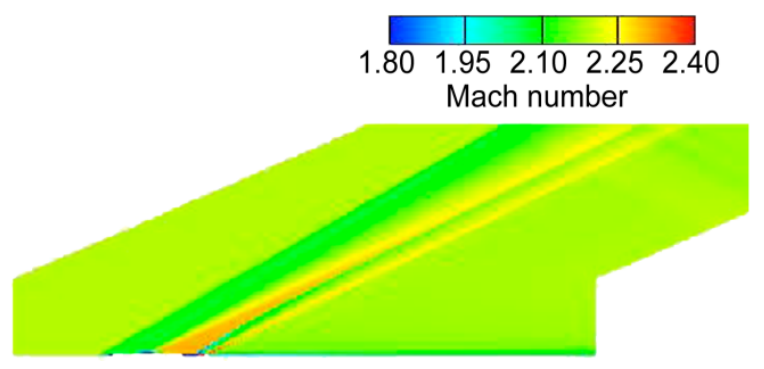

Figure 11. Slot nozzle at NPR 16. 


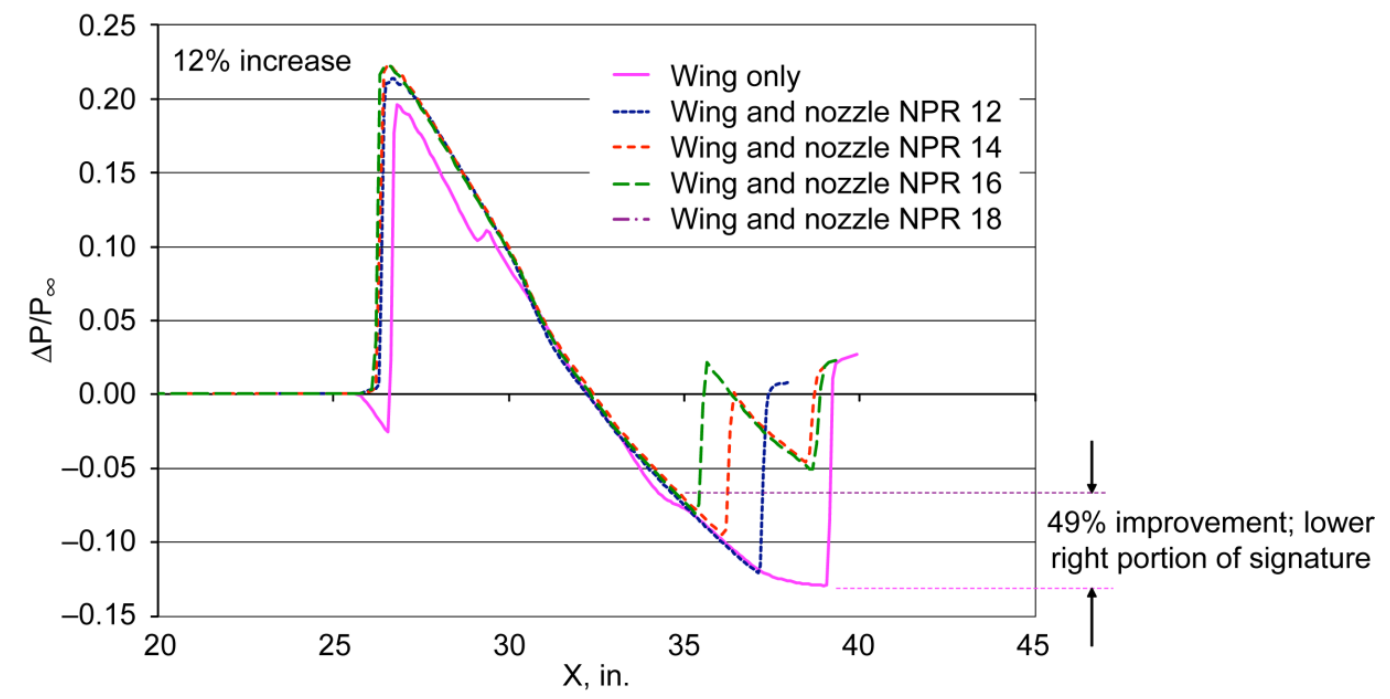

Figure 12. $\Delta \mathbf{P} / \mathbf{P}_{\infty}$ comparisons for baseline wing and wing with integrated slot nozzle operating at NPR of 12, 14, 16, and 18.

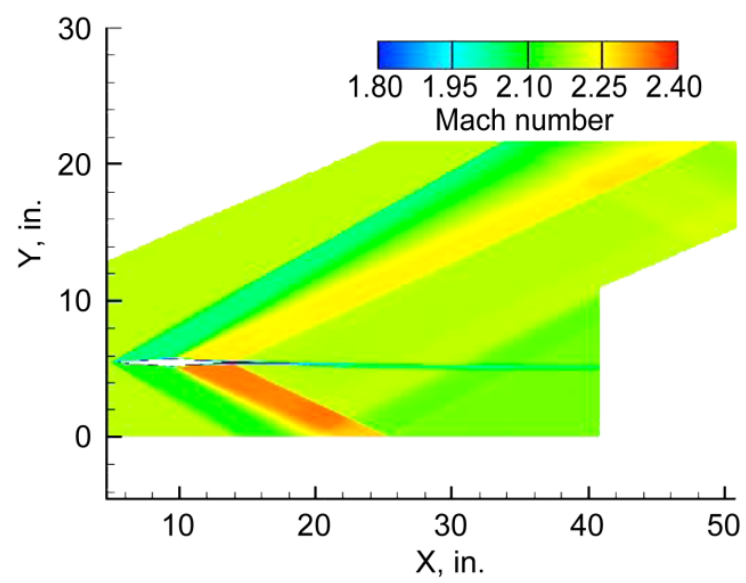

Figure 13. Mach number contours for wing only at $1^{\circ}$ angle of attack.

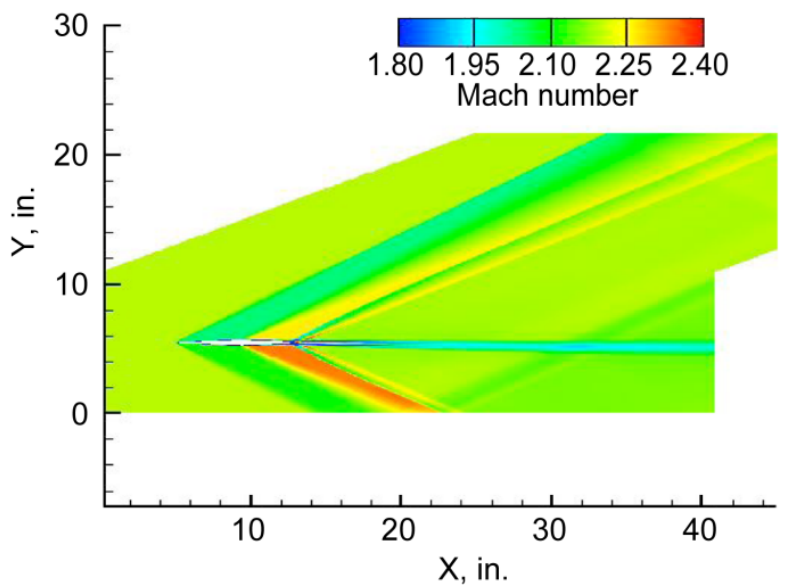

Figure 14. Mach number contours for wing with integrated slot nozzle at $1^{\circ}$ angle of attack, NPR 18.

The reduction in expansion caused by the wing can be seen in the $\Delta \mathrm{P} / \mathrm{P}$ plot in Fig. 12, taken at a distance of 15 in. above the wing centerline. The baseline wing pressure profile is displayed again, with pressure profiles for the wing and slot nozzle configuration. Nozzle pressure ratio was increased from 12 to 18 , causing a dramatic reduction in the expansion pressures observed in the lower right portion of the pressure signature. Values change from -0.129 to -0.067 , a 49 percent improvement based on atmospheric pressure. In this simulation, there was a 12 percent increase in the leading edge shock at the wing. The increase was caused by the nozzle plume, creating a thickened boundary layer at the aft end of the wing, which feeds back to the leading edge. This problem would typically be mitigated with wing sweep, which would reduce the overall magnitude of the near field pressures, but was not considered here.

\section{Wing and Wing With Slot Nozzle at $1^{\circ}$ Angle of Attack}

Mach number contours in Fig. 13 are for a modified two-dimensional wing. The previous simulation was an upper wing surface with a slot nozzle simply placed under the wing trailing edge. To add some reality to this concept, the wing was made thicker and longer in order to accommodate the embedded slot nozzle configuration. The wing was $2.002 \mathrm{in.} \mathrm{longer} \mathrm{and} 0.094 \mathrm{in}$. thicker, to accommodate the nozzle with exit height of $0.094 \mathrm{in}$. Results with the nozzle are shown in Fig. 14 for comparison. Recall that free stream conditions were Mach 2.2 with a $-1^{\circ}$ angle of attack, where the model is upside down in this simulation. Similar to results in Fig. 7 for the baseline wing configuration at 


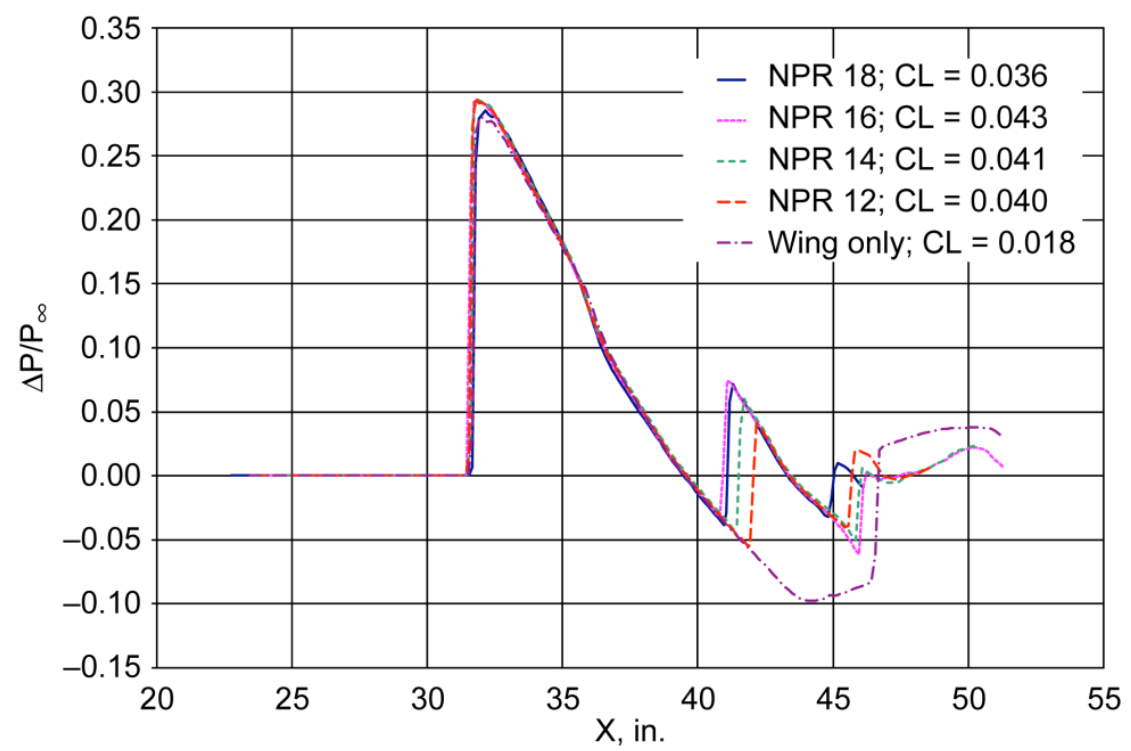

Figure 15. $\Delta P / P_{\infty}$ comparisons for baseline wing and wing with integrated slot nozzle operating at NPR of 12, 14, 16, and 18.

Mach 2.2 there are a clear shock and compression from the leading edge and forward part of the wing, followed by a dramatic expansion; and finally a shock back to ambient pressure. In Fig. 14, the embedded slot nozzle is operating at a NPR of 18, and the expansion wave on the aft portion of the wing is substantially reduced by the shock at the nozzle lip.

The reduction in expansion caused by the wing at $1^{\circ}$ angle of attack can be seen in the $\Delta \mathrm{P} / \mathrm{P}$ plot in Fig. 15 , taken at a distance of $15 \mathrm{in}$. above the wing centerline. The baseline wing pressure profile is displayed, with pressure profiles for the wing and slot nozzle configuration. Nozzle pressure ratio was increased from 12 to 18 , causing a dramatic reduction in the wing expansion pressures from -0.097 to -0.037 , a 62 percent improvement based on atmospheric pressure. These trends are nearly identical to results at $0^{\circ}$ angle of attack, and demonstrate that this technique is applicable with lift. It is also noted that the lift coefficient changes for this configuration as NPR varies between 12 and 14 . The wing only configuration has a lift coefficient of 0.018 , while the configuration with the slot nozzle has lift coefficients that vary between 0.036 and 0.043 .

\section{Thrust Performance}

Thrust coefficient is given in Fig. 16 for the wing with slot nozzle at $0^{\circ}$ angle of attack. The design point for this nozzle was Mach 1.4 at a NPR of 8 . This was a study on highly underexpanded nozzle effects for sonic boom reduction, so the design point was not relevant and not presented. For highly under-expanded nozzle flow conditions, NPR from 12 to 18 are not the optimal operating points and the thrust coefficient drops from 0.94 to nearly 0.91 . While this result is somewhat disappointing, this study is the first study on a slot nozzle concept as applied to sonic boom reduction, and is not an optimized solution.

It may be possible to optimize thrust and still obtain a reasonable reduction in near field pressures. Also, trailing edge slot nozzles could be sized to provide main propulsion, auxiliary propulsion, or blowing for sonic boom reduction through flow control. A simple trade study was performed to study the effect of slot nozzle design to determine if efficiency could be improved, and results are shown in Fig. 17.

A variety of slot nozzle designs were developed by Keech and Castner. ${ }^{8}$ Nozzles consisted of the baseline Mach 1.4 design used earlier in this report, a Mach 1.8 design and a Mach 2.0 design. The throat height of the Mach 2.0 nozzle design was modified for a "Double Height" and "Quad Height" configuration; flow area was not kept constant as this was a two-dimensional simulation. Results were plotted with thrust coefficient versus the magnitude (absolute value) of the lower right portion of the near field pressure signature ( $\mathrm{N}$-wave). In this case, a higher thrust coefficient indicates better performance, and a lower value from the right portion of the N-wave indicates the potential for lower sonic boom contribution. The Mach 2.0 "Quad Height" nozzle displayed the best overall thrust performance, while still maintaining an improvement in the sonic boom pressure signature. Differences in contour plots for these cases were subtle, and were similar to comparisons between Figs. 9, 10, and 11. As a result, additional color contours are not presented. 


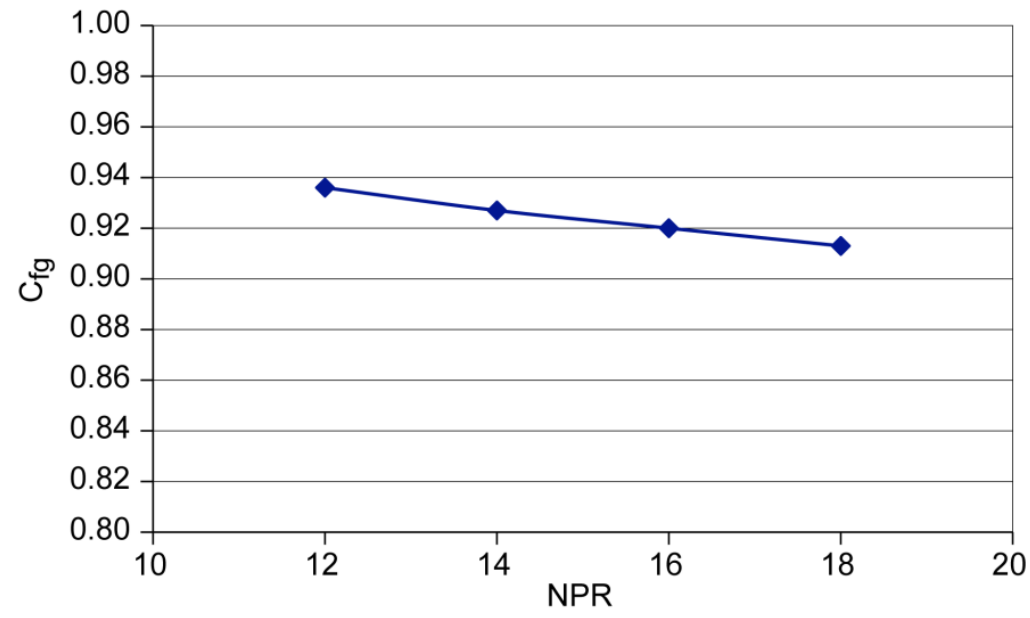

Figure 16. Thrust performance for integrated slot nozzle from NPR 12 to 18 at $0^{\circ}$ angle of attack.

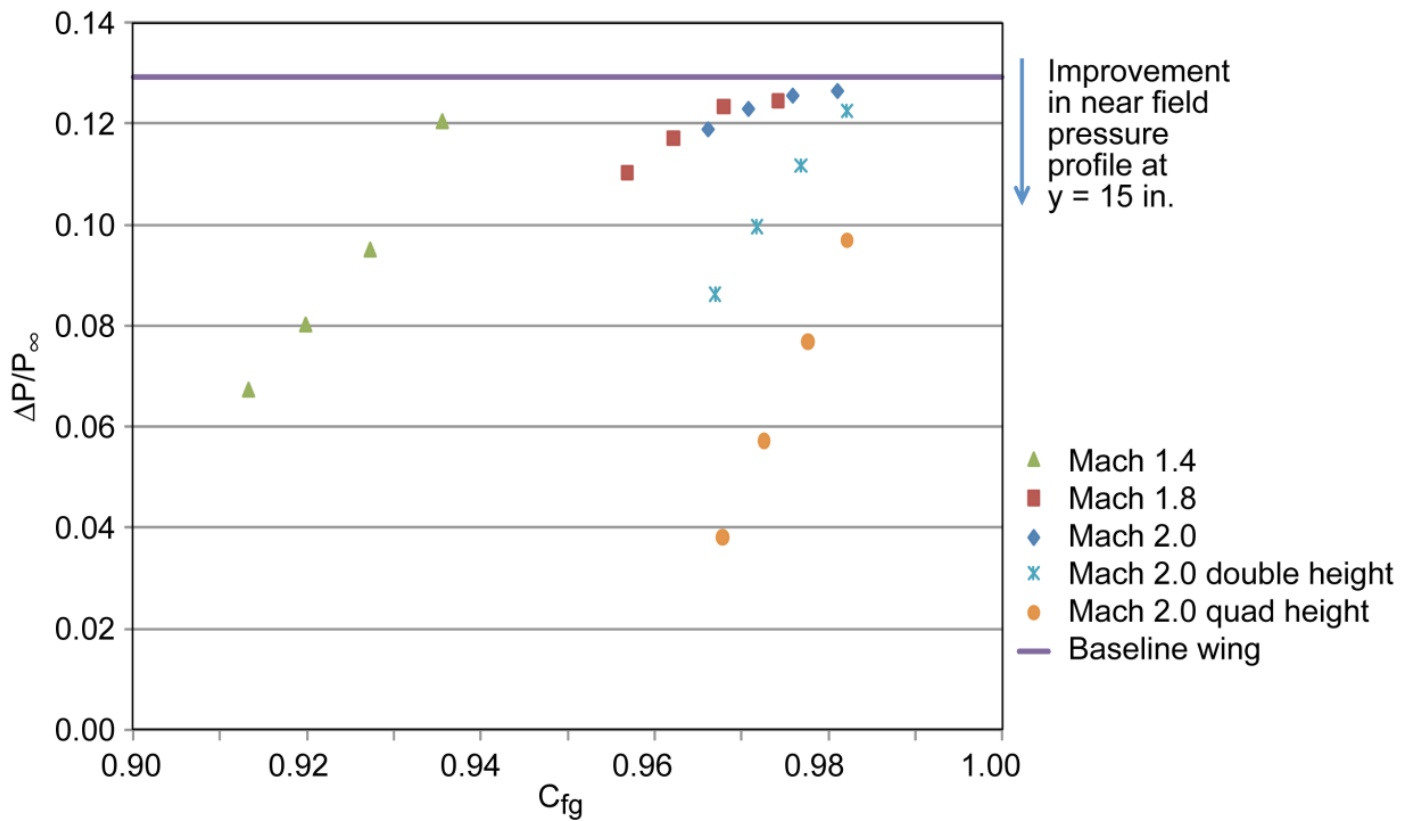

Figure 17. Sonic boom magnitude (absolute value) from lower right portion of the near field pressure signature versus nozzle efficiency. 


\section{Conclusions}

This CFD study demonstrates the feasibility of controlling an expansion shock from a supersonic wing with an integrated slot nozzle configuration. A reduced shock expansion could result in a reduced sonic boom signature. The size and configuration of the slot nozzle needs further study. Future studies could explore how this concept could be best applied for main propulsion, auxiliary propulsion, or flow control.

Thrust performance of the baseline Mach 1.4 nozzle and wing configuration was disappointing, but further studies showed that changing the size and aspect ratio of a slot nozzle has potential benefits in thrust performance and sonic boom contribution.

\section{References}

${ }^{1}$ D. Graham, J. Dahlin, K. Meredith, J. Vadnais: Aerodynamic Design of Shaped Sonic Boom Demonstration Aircraft, AIAA-2005-0009.

${ }^{2}$ D. Freund, D. Howe, F. Simmons, L. Schuster: Quiet Spike Prototype Aerodynamic Characteristics from Flight Test, AIAA-2008-125.

${ }^{3}$ Castner, R.S.: Analysis of Plume Effects on Sonic Boom Signature for Isolated Nozzle Configurations AIAA-2008-3729, June 2008.

${ }^{4}$ Bui, T.T., CFD Analysis of Nozzle Jet Plume Effects on Sonic Boom Signature, AIAA-2009-1054, Jan 2009.

${ }^{5}$ Putnam, L.E. and Capone, F.J.: Experimental Determination of Equivalent Solid Bodies to Represent Jet Exhausts into a Mach 2.2 External Stream, NASA TN D-5553, 1969.

${ }^{6}$ Hunton, L.W., Hicks, R.M. and Mendoza, J.P: Some Effects of Wing Planform on Sonic Boom, NASA TN-D-7160, Jan 1973.

${ }^{7}$ R.H. Bush, G.D. Power, C.E. Towne: WIND: The Production Flow Solver of the NPARC Alliance, AIAA Paper 98-0935.

${ }^{8}$ Keech, S.C. and Castner, R.S.: Reduction of Sonic Boom From Manipulation of Slot Nozzle Exhaust Plumes, USRP Internship Final Report, NASA Glenn Research Center, August 2009. 